\title{
Under-reporting of Adverse Drug Reactions among Healthcare Professionals in Brazil: An Estimate Based on National Pharmacovigilance Survey
}

\author{
José Romério Rabelo Melo ${ }^{1,2, *}$ Elisabeth Carmen Duarte ${ }^{3}$, Karla de Araújo Ferreira ${ }^{1,4}$, Yannie Silveira Gonçalves ${ }^{1,4}$, \\ Marcelo Vogler de Moraes ${ }^{1,4}$, Paulo Sergio Dourado Arrais ${ }^{5}$ \\ 'Brazilian Health Regulatory Agency (Anvisa)/ Brasília-DF, BRAZIL. \\ ${ }^{2}$ Graduate Program of Pharmaceutical Sciences - Federal University of Ceará (UFC), Fortaleza-CE, BRAZIL. \\ ${ }^{3}$ Epidemiology at Tropical Medicine Center, Faculty of Medicine, University of Brasilia. Brasilia-DF, BRAZIL. \\ ${ }^{4}$ National Medicines Monitoring Center (CNMM) / Brazilian Health Regulatory Anvisa), Brasília-DF, BRAZIL. \\ 5Department of Pharmacy, Faculty of Pharmacy, Dentistry and Nursing, Federal University of Ceará. Fortaleza-CE, BRAZIL.
}

\begin{abstract}
Background: Adverse Drug Reaction (ADR) is a public health problem with an impact on health care costs. Spontaneous reporting comprises the primary method for detection ADR's. However, high levels under-reporting represents a barrier in pharmacovigilance. Objectives: The present study aims to estimate the prevalence of under-reporting ADR professionals in Brazil and to analyze the factors associated with under-reporting. Methods: Used a cross-sectional study based on an online survey for healthcare professionals conducted by the Brazilian Health Regulatory Agency (Anvisa). Unconditional logistic regression was performed and adjusted odd ratios (OR) were estimated. Results: In total 789 questionnaires were analyzed and based on the criteria, $67.5 \%$ of professionals were considered under-reporters. The main reason for under-reporting was the lack of access to vital data for notification (33.8\%). $52.7 \%$ of the participants stated that the existence of a simpler system to notify motivated its use. It was found that residents in the Southern region of Brazil have 2.3 times the chance of under-reporting an ADR than those in the Southeast region (OR $=2.3$; IC 95\%:1.3-4.2). Having advanced knowledge in pharmacovigilance IOR=0.5; IC 95\%: 0.4-0.7) and performing notification even without the
\end{abstract}

causal certainty of the event (OR $=0.5$; IC 95\%:0.3-0.7) were protective factors for under-reporting, while not applicating knowledge routinely was considered a risk factor for under-reporting (OR = 4.4; IC 95\%:2.1-9.2). Conclusion: $\mathrm{A}$ high rate of professionals considered as under-reporters of ADRs in Brazil has been detected. This study will make an important contribution to health managers and drug regulators for strengthen the national pharmacovigilance system.

Key words: Drug-Related Side Effects and Adverse Reactions, Pharmacovigilance, Adverse Drug Reaction Reporting Systems, Health Care Coordination and Monitoring, Health Education.

Correspondence

Mr. José Romério Rabelo Melo

Brazilian Health Regulatory Agency (Anvisa)/ Brasília-DF, BRAZIL.

Phone: +85-98208-3808

Email: romerio.pgcf@gmail.com

DOI: 10.5530/jyp.2020.12.92

\section{INTRODUCTION}

Adverse Drug Reactions (ADRs) are increasingly important issues for public health and their incidence is increasing worldwide, with high rates of morbidity and mortality and rises health care costs. ${ }^{1-3}$ ADR detection, evaluation and prevention are responsibilities of Pharmacovigilance, while voluntary notification plays an important role in the surveillance of these events, especially for those not identified in clinical studies. Its advantages are the identification of risk factors that predispose to the toxicity of drugs and the good relationship between cost and effect in monitoring the effectiveness and safety of drugs used in public health programs. ${ }^{4,5}$

On the other hand, the main restriction of voluntary notification is under-reporting, ${ }^{4,6,7}$ which can reach up to $95 \%$ of cases, ${ }^{5,8}$ inhibiting accurate estimates of the occurrence of events and hindering effective intervention measures by drug regulatory agencies. In Brazil, most spontaneous notifications are made by health professionals and those connected to hospitals in the Sentinela Network, which is a Brazilian active observatory of the performance and safety of health products under health surveillance. ${ }^{9}$
The present study aims to estimate the under-reporting of ADR events, on a voluntary basis, by health professionals in Brazil and to analyze the factors associated with this in different Brazilian regions.

\section{MATERIALS AND METHODS}

\section{Study design}

This research is a cross-sectional study with descriptive-exploratory and analytical stages. This study was based on a survey about pharmacovigilance and notification of ADR conducted by the Brazilian Health Regulatory Agency (Anvisa) from January to April 2019.10 The research was inserted in the context of the Health Surveillance practice, specifically in the pharmacovigilance actions of Anvisa. As it does not require identification of the subjects in the research, it was not necessary to submit the study to the Research Ethics Committee, following Resolution No. 510/2016, of the Brazilian National Health Council.

\section{Study questionnaire}

This study was based on three questions from the questionnaire and was opened to be answered by any Health professional in Brazil through 
a link to the Anvisa website (http://portal.Anvisa.gov.br/noticias). The questionnaire was disclosed to the institutions of the Sentinel Network, in addition to professional councils, unions, associations of the pharmaceutical industries and medical associations.

\section{Study Population}

The target populations were nurses, pharmacists, physicians and "other" professionals. Those participants who answered any of the reasons for not sending the available notification at any given moment in life for the question "What are the reasons that led you to not notify the ADR?" were considered as under-reporters. The participants who marked "Not applicable" as answer were considered as notifiers for ADR.

\section{Inclusion criteria}

Being a healthcare professional with a higher education was used as inclusion criteria, while the exclusion criteria adopted was a questionnaire with less than $80 \%$ of answered questions related to ADR under-reporting.

\section{Statistical analysis}

In the descriptive stage, the variables of interest were categorized and described by means of relative frequencies. The data was submitted to unconditional logistic regression. The dependent variable defined is "being under-reporter (yes/no)", while the following sociodemographic variables were defined as independent: education, age group, region of residence, professional category and general knowledge about pharmacovigilance and the ADR notification process.

In the analytical stage, bivariate and multivariate logistic regression models were used. Initially, in the bivariate analysis, variables that were candidates for multiple analysis were identified with a significance level of $p<0.20$. Subsequently, in the multivariable models, the manually guided stepwise (backwards) method was used to handly eliminate less statistically relevant variables until only explanatory (independent) variables with statistical significance $(p<0.05)$ remained in the final model. Measurements of the adjusted odd ratios (OR) and their 95\% confidence intervals (95\% CI) were estimated. The entire analysis was performed using the Stata ${ }^{\circ}$ software version 10.

\section{RESULTS}

In total 789 questionnaires were analyzed. Pharmacists, nurses, physicians and "other" professionals represented $73.6 \%, 18.2 \%, 4.6 \%$ and $3.6 \%$ of participants, respectively. Most participants were aged between 25 and 44 years old $(81.9 \%)$. Respondents from the Southeast region of Brazil represented 54.7\%.

Regarding the practice of notification, among those who answered this question $(n=714), 67.5 \%$ decided not to report an identified ADR, this measure being considered representative for the prevalence of underreported professionals for at least once in their lives.

The three main reasons mentioned by participants for not notifying ADR were: lack of access to the data necessary to fill the notification form (33.7\%), difficulties in accessing the form due to technical problems, such as browser incompatible with the computer version, instability in the notification system, incompatibility with smartphones, among others (23.4\%), not having enough time to report $(21.6 \%)$, as represented in Table 1.

Among the reasons reported by health professionals that could encourage them to start notifying $\mathrm{ADR}$ or increase the number of notifications, the most frequent were: the creation of a simpler system for notification $(52.7 \%)$, the reception of feedback from system managers about notifications previously made $(35.2 \%)$, the possibility of making notifications via mobile phone (34.4\%), as represented in Table 2.

Health professionals were also asked what the criteria were used to define their decisions for notifying ADRs. It was observed that $54.9 \%$ of the participants reported suspected cases of ADR even when not sure about the causality between the medication and the adverse event. This notification criterion was answered by $68.8 \%$ of physicians and $60.3 \%$ of nurses, as represented in Figure 1.

The notification of cases only after conviction that the medication caused the event (causative agent) was the criterion adopted by $34.6 \%$ of the participants. The professionals who most reported notifying only after

Table 1: Reasons reported by health professionals for not sending a notification to the agency responsible for monitoring ADR, Brazil, $2019(n=482) *$

\begin{tabular}{|c|c|c|c|c|c|}
\hline \multirow[t]{2}{*}{ Reasons presented } & $\begin{array}{l}\text { Nurse } \\
n=82\end{array}$ & $\begin{array}{c}\text { Pharmacist } \\
n=367\end{array}$ & $\begin{array}{c}\text { Physician } \\
n=21\end{array}$ & $\begin{array}{l}\text { Other } \\
n=12\end{array}$ & $\begin{array}{c}\text { Total } \\
n=482\end{array}$ \\
\hline & $n(\%)$ & $n(\%)$ & $n(\%)$ & $n(\%)$ & $n(\%)$ \\
\hline Lack of data needed to notify & $23(28,1)$ & $131(35,7)$ & $4(19,1)$ & $4(36,3)$ & $162(33,7)$ \\
\hline $\begin{array}{l}\text { Difficulties in the access of the questionnaire } \\
\text { due to technical problems }\end{array}$ & $25(30,4)$ & $80(21,8)$ & $7(33,3)$ & $1(9,1)$ & $113(23,4)$ \\
\hline Lack of enough time to report & $16(19,5)$ & $77(20,9)$ & $6(28,6)$ & $5(45,4)$ & $104(21,6)$ \\
\hline Lack of feedback from last notification & $22(26,8)$ & $71(19,3)$ & $6(28,6)$ & $3(27,3)$ & $102(21,2)$ \\
\hline Notifying is a complex process & $13(15,8)$ & $53(14,4)$ & $6(28,6)$ & $2(18,2)$ & $74(15,4)$ \\
\hline Do not know how to notify & $4(4,9)$ & $39(10,6)$ & $4(19,1)$ & $0(0,0)$ & $47(9,8)$ \\
\hline Do not know to whom notify & $1(1,2)$ & $27(7,4)$ & $3(14,3)$ & $2(18,2)$ & $33(6,9)$ \\
\hline Do not share patient and personal data & $1(1,2)$ & $15(4,1)$ & $1(4,8)$ & $0(0,0)$ & $17(3,5)$ \\
\hline $\begin{array}{l}\text { Do not understand what is done with the } \\
\text { notification provided }\end{array}$ & $3(3,7)$ & $10(2,7)$ & $1(4,8)$ & $1(9,1)$ & $15(3,1)$ \\
\hline Do not see its importance & $0(0,0)$ & $5(1,4)$ & $1(4,8)$ & $1(9,1)$ & $7(1,4)$ \\
\hline $\begin{array}{c}\text { Do not share data regarding my clinical } \\
\text { conduct }\end{array}$ & $0(0,0)$ & $2(0,5)$ & $1(4,8)$ & $0(0,0)$ & $3(0,6)$ \\
\hline Did not reply & 13 & 52 & 2 & 7 & 74 \\
\hline
\end{tabular}

* The question exactly was "What were the reasons that made you decide not to report Adverse Events? Please select the applicable responses." 
confirming causality were "other" professionals' category, with $40 \%$, as represented in Figure 1.

\section{Analysis of factors associated with under-reporting of ADR}

A higher prevalence of under-reporters (in life) was identified among health professionals residing in the Southern region of Brazil (82.2\%), while the lowest prevalence was observed among residents of the Southeast region (61.8\%) (Table 3). It was found that a health professional who lives in the Southern region has 2.3 times the chance of being a under-reporter professional compared to residents from the Southeast region $(\mathrm{OR}=2.3 ; 95 \% \mathrm{CI}=1.3$ to $4.2 ; p<0.01)$. Residents from other regions have a prevalence of this behavior similar to the residents from the Southeast region, as represented in Table 3.

Among health professionals who claimed to have advanced knowledge and / or to have these concepts as part of their daily routine, $49.8 \%$ were under-reporters, while considering all groups, this prevalence was $76.6 \%$. In the multivariable analysis, this association was statistically significant, indicating that having this type of knowledge was a protective factor against under-reporting $\mathrm{ADR}(\mathrm{OR}=0.5 ; 95 \% \mathrm{CI}=0.4$ to 0.7 ), as represented in Table 3 .

Considering professionals that report even without being sure about the causal relationship between the event and the use of the medication, $56.5 \%$ of them were considered under-reporters, while this rate increased to $77.2 \%$ considering all groups. This association was statistically

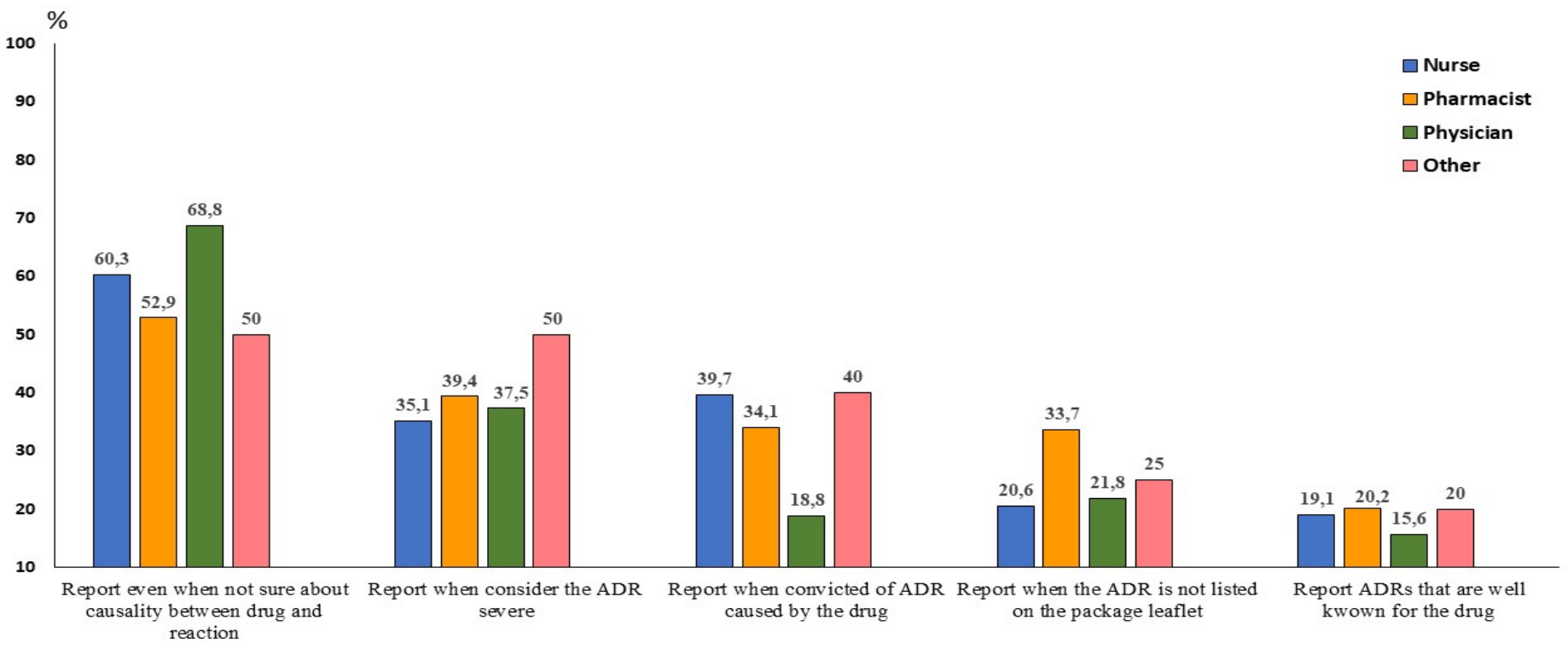

Figure 1: Criteria referred by health professionals for notification of ADRs, Brazil, $2019(n=693)^{*}$

Table 2: Reasons, reported by health professionals, that could contribute to reduce the under-reporting of ADR, Brazil, 2019 $(n=699) *$.

\begin{tabular}{|c|c|c|c|c|c|}
\hline \multirow[t]{2}{*}{ Reasons presented } & $\begin{array}{l}\text { Nurse } \\
n=127\end{array}$ & $\begin{array}{c}\text { Pharmacist } \\
n=520\end{array}$ & $\begin{array}{c}\text { Physician } \\
n=34\end{array}$ & $\begin{array}{l}\text { Other } \\
n=18\end{array}$ & $\begin{array}{c}\text { Total } \\
n=699\end{array}$ \\
\hline & $n(\%)$ & $n(\%)$ & $n(\%)$ & $n(\%)$ & $n(\%)$ \\
\hline Simpler system & $61(48,0)$ & $271(52,1)$ & $25(73,5)$ & $11(61,1)$ & $368(52,7)$ \\
\hline Feedback of notifications & $45(35,4)$ & $183(35,2)$ & $11(32,3)$ & $7(38,9)$ & $246(35,2)$ \\
\hline Notifying via mobile phone & $38(29,9)$ & $178(34,2)$ & $16(47,1)$ & $9(50,0)$ & $241(34,4)$ \\
\hline $\begin{array}{c}\text { Notifying via electronic } \\
\text { prescription / dispensing system }\end{array}$ & $38(29,9)$ & $134(25,8)$ & $15(44,1)$ & $03(16,7)$ & $190(27,2)$ \\
\hline $\begin{array}{l}\text { Instructions on which cases should } \\
\text { be reported }\end{array}$ & $40(31,5)$ & $130(25,0)$ & $6(17,7)$ & $5(27,8)$ & $181(25,9)$ \\
\hline $\begin{array}{l}\text { Instructions on how to perform } \\
\text { notifications }\end{array}$ & $23(18,1)$ & $92(17,7)$ & $05(14,7)$ & $04(22,2)$ & $124(17,7)$ \\
\hline $\begin{array}{l}\text { Instructions on what is done with } \\
\text { the notification }\end{array}$ & $23(18,1)$ & $90(17,3)$ & $05(14,7)$ & $05(27,8)$ & $123(17,6)$ \\
\hline $\begin{array}{l}\text { Instructions on to whom send the } \\
\text { notifications }\end{array}$ & $13(10,2)$ & $54(10,4)$ & $07(20,6)$ & $02(11,1)$ & $76(10,9)$ \\
\hline Did not reply & 17 & 61 & 2 & 10 & 90 \\
\hline
\end{tabular}

*The question was "In your opinion, what could help you to start notifying or increase the number of ADR notifications you already do. Please select the applicable answers." 
Table 3: Proportion (\%) and associated factors (1) to the practice of not report an ADR derived from raw and adjusted logistic regression analysis, Brazil, 2019.

\begin{tabular}{|c|c|c|c|c|c|}
\hline \multirow[t]{2}{*}{ Variable } & \multirow{2}{*}{$\begin{array}{l}\% \text { Under- } \\
\text { reporters }\end{array}$} & \multicolumn{2}{|c|}{ Raw analysis } & \multicolumn{2}{|c|}{$\begin{array}{l}\text { Multivariate analysis (final } \\
\text { model) } n=675\end{array}$} \\
\hline & & OR & IC\% (p) & OR & IC $\%(p)$ \\
\hline \multicolumn{6}{|l|}{ Region } \\
\hline Southeast & 61,8 & Ref & & Ref & \\
\hline North & 75,0 & 1,9 & $0,8-4,2(0,14)$ & 1,30 & $0,5-3,2(0,55)$ \\
\hline Northeast & 70,3 & 1,5 & $0,9-2,2(0,08)$ & 1,33 & $0,8-2,1(0,22)$ \\
\hline Central-West & 69,0 & 1,4 & $0,8-2,5(0,29)$ & 0,8 & $0,4-1,6(0,62)$ \\
\hline South & 82,2 & 2,8 & $1,6-4,9(<0,01)$ & 2,3 & $1,3-4,2(<0,01)$ \\
\hline \multicolumn{6}{|c|}{ Professional category } \\
\hline Pharmacist & 69,5 & Ref & & & \\
\hline Nurse & 62,6 & 0,7 & $0,5-1,1(0,12)$ & - & \\
\hline Physician & 61,8 & 0,7 & $0,3-1,5(0,34)$ & - & \\
\hline Other & 57,1 & 0,6 & $0,2-1,4(0,23)$ & - & \\
\hline \multicolumn{6}{|l|}{ Age range } \\
\hline$<25$ years & 82,6 & Ref & & & \\
\hline $25-34$ years & 68,4 & 0,4 & $0,2-1,4(0,16)$ & - & \\
\hline $35-44$ years & 67,4 & 0,4 & $0,1-1,3(0,14)$ & - & \\
\hline$\geq 45$ years & 61,3 & 0,3 & $0,1-1,1(0,06)$ & - & \\
\hline \multicolumn{6}{|c|}{ Holds a postgraduate degree } \\
\hline No & 72,1 & & & & \\
\hline Yes & 65,8 & 0,7 & $0,5-1,1(0,11)$ & - & \\
\hline \multicolumn{6}{|c|}{$\begin{array}{l}\text { Acquired knowledge of PV at undergraduate } \\
\text { courses }\end{array}$} \\
\hline No & 64,0 & & & & \\
\hline Yes & 85,3 & 3,2 & $1,9-5,6(<0,01)$ & - & \\
\hline \multicolumn{6}{|c|}{$\begin{array}{c}\text { Acquired knowledge of } \mathrm{PV} \text { at postgraduate } \\
\text { education }\end{array}$} \\
\hline No & 66,5 & & & & \\
\hline Yes & 74,7 & 1,4 & $0,9-2,4(0,12)$ & - & \\
\hline \multicolumn{6}{|c|}{$\begin{array}{l}\text { Acquired knowledge of PV at training/extension } \\
\text { courses }\end{array}$} \\
\hline No & 68,7 & & & & \\
\hline Yes & 63,4 & 0,8 & $0,5-1,1(0,20)$ & - & \\
\hline \multicolumn{6}{|c|}{ Has advanced knowledge on PV } \\
\hline No & 76,6 & & & & \\
\hline Yes & 49,8 & 0,3 & $0,2-0,4(<0,01)$ & 0,5 & $0,4-0,7(<0,01)$ \\
\hline \multicolumn{6}{|c|}{ Has knowledge on PV, but do not apply it } \\
\hline No & 61,7 & & & & \\
\hline Yes & 93,1 & 8,3 & $4,1-16,7(<0,01)$ & 4,4 & $2,1-9,2(<0,01)$ \\
\hline \multicolumn{6}{|c|}{ Does not know or has never heard of PV } \\
\hline No & 66,6 & & & & \\
\hline Yes & 88,9 & 4,0 & $1,2-13,4(0,02)$ & - & - \\
\hline \multicolumn{6}{|c|}{ Notifies ADR even when not sure about causality } \\
\hline No & 77,2 & & & & \\
\hline Yes & 56,5 & 0,4 & $0,3-0,5(<0,01)$ & 0,5 & $0,3-0,7(<0,01)$ \\
\hline \multicolumn{6}{|c|}{$\begin{array}{l}\text { Notifies ADR only when events are not listed on } \\
\text { the package leaflet }\end{array}$} \\
\hline No & 68,7 & & & & \\
\hline Yes & 59,1 & 0,65 & $0,4-0,9(0,01)$ & - & \\
\hline
\end{tabular}


Notifies ADR that are widely known

No

69,2

Yes 51,1

$0,4 \quad 0,3-0,7(<0,01)$

0,6

$0,4-0,9(0,02)$

(1) Associated factors identified through raw and multiple logistic regression analysis, with the dependent variable (yes/no). OR-Odds Ratio; $\mathrm{IC}_{95 \%}-95 \%$ of Confidence Intervals; PV = pharmacovigilance.

* 74 professionals did not answer the question about not notifying the ADR.

** Variables with $p<0.20$, evaluated in the multivariable model with a manually guided stepwise process, were removed if $p>0.05$ or maintained if $p<=0.05$.

significant, indicating that reporting without certainty of causality is a protective behavior against the practice of under-reporting ADRs (OR = $0.5 ; 95 \% \mathrm{CI}=0.3-0.7$ ), as represented in Table 3 .

Professionals who claim to have the habit of notifying ADRs that are widely known were less under-reporters (51.1\%) than the others $(69.2 \%)$ and this association was statistically significant $(\mathrm{OR}=0.6 ; 95 \% \mathrm{CI}=0$, 4-0.9), as represented in Table 3.

Considering the age group, it was observed a reduction in underreporting as the age increases, with prevalence of under-reporting agents from $82.6 \%$ at the age group of less than 25 years old going down to $61.3 \%$ at the group of 45 or older, but this reduction is not statistically significant.

For those professionals who reported having obtained knowledge about pharmacovigilance at undergraduate education, $85.3 \%$ were underreporting, while for the others this prevalence was $64.0 \%(p<0.01)$. However, in the multivariate analysis, no association was confirmed between the place of obtaining knowledge in pharmacovigilance and this behavior, as represented in Table 3 .

\section{DISCUSSION}

In the present study, the under-reporting of ADR among health professionals - at least once in their lives - was considered high. Pharmacists were the most under-reporters, followed by nursing professionals. The southern region had the highest level of underreporters, well above the national average. The main reasons listed that discourage professionals to report an ADR were the following: lack of access to vital information necessary for the notification of the case, difficulties with information technology. The factors associated with the chance of being an under-reporter were being a resident in the south and not applying pharmacovigilance knowledge in your professional practice. The protective factors were having advanced knowledge in pharmacovigilance, notifying ADR even in the uncertainty of causality and notifying the events widely known associated with the use of a certain medication.

The under-reporting of ADRs still remains as a challenge for many health managers and drug regulators in many countries.,8 A Brazilian study identified low reporting rates in Brazil (29/1 million inhabitants), being even lower than the rates in South Africa (77/1 million inhabitants), therefore markedly lower than the recommended values by the WHO. ${ }^{9}$ The rate found on this research was higher than the rate found in Ethiopia (53.9\%) ${ }^{11}$ but lower than the studies conducted in Saudi Arabia, which was $88.8 \%,{ }^{12}$ and lower than the study Indian, with an under-reporting rate of $74.5 \% .^{13}$

Even in countries that have consolidated pharmacovigilance systems, the main reasons that discouraged professionals from reporting ADR were similar to the reasons listed on the present study, ${ }^{1,5,14}$ such as the lack of access to information necessary for the notification of the case, difficulties with information technology, lack of time and lack of feedback to the notifiers. These reasons presented here are also in line with what Inman (1996) $)^{15}$ classified as "seven deadly sins", which fit in three categories of "sins": indifference or lack of interest in $83 \%$ cases, ignorance in $14 \%$ of cases and lastly the fear of sharing personal and patient data, in $3 \%$ of cases.

Among the reasons classified as "sins of indifference", nursing professionals were the ones that most presented this type of sin. The doctors were the ones who most presented the reasons for not reporting due to ignorance and fear. These reasons are directly related to the personal and professional characteristics of health workers and their knowledge and attitudes towards the notification of ADRs.

Among the reasons reported for not notifying, it was observed that younger health professionals (less than 25 years old) do not know how to report and to whom report ("sin of ignorance") and older professionals (over 45 years old) do not notify because they are not comfortable sharing their medical practice ("sin of fear"). A hypothesis that could explain the results for the younger professionals might be due to the lack experience added to the poor education provided for them. In fact, that as the age of the health professional increases, the knowledge and the likelihood of reporting an ADR also increase. ${ }^{16}$

Among the factors that could influence professionals to notify ADRs, or even increase the number of reports, the main were: the availability of a less complex notification system, receiving more feedback from regulatory managers on the resolution of the reasons that led to the occurrence of ADR, possibility of notification via cell phone or via electronic prescription/dispensation system itself. It can be seen that two of the main responses are linked to the possibility of using digital tools. Studies show that technology can help to increase reports of ADRs and to make health professionals more satisfied, which may result in an increase in the number of notifications sent by digital systems. ${ }^{17}$

It was also observed in the multiple regression analysis that having advanced level of knowledge in PV and applying it at work is a protective factor against under-reporting. On the other hand, having the knowledge but not using it in the daily routine, in the present study, was a risk factor, increasing the chance of being under-reporter by 4.4 times. It is known that adequate knowledge can improve the professional's attitude. However, it is not decisive, since if the health professional keeps negative attitudes, it certainly will not change his practice of under-reporting $\mathrm{ADR}$, which demonstrates that the difference between knowledge and practice is high in pharmacovigilance. ${ }^{18}$

In the analysis of the question that dealt with the criterion used to decide whether to notify or not, it was observed that most participants decided to report even when uncertain of the causality between drug and adverse reaction, while others stated that they would notify only if the adverse reaction was severe and would notify only if they were sure about the causality between drug and adverse reaction. Similar results were identified in a study with nurses ${ }^{19}$ and in research with European doctors. ${ }^{14}$ 
In the multivariate analysis, it was observed that notifying even uncertain of causality behaved as a protective factor against under-reporting. Notifying the ADR only when you are sure of the causality between the medication and the reaction clearly demonstrates ignorance and that the professional is not sensitive to the actions of pharmacovigilance. This attitude was also identified in other studies with healthcare professionals. ${ }^{16}$ The immediate notification of suspected cases of ADR, in an objective way, is the most efficient method for surveillance of drug safety.

The present study also showed that the practice of notifying, even events that are widely known for a certain drug, was a protective factor against under-reporting. Notification of all suspected drug events (described or not in package leaflets) is extremely necessary, especially in the stages of structuring any pharmacovigilance system, since this conduct creates a culture of reporting for drug safety. ${ }^{4}$

This research has limitations, such as selection bias, since the sample studied did not meet a probabilistic process. As one of the methods consisted of obtaining responses from candidates through an open link on the Anvisa website, it is possible that professionals already engaged in pharmacovigilance activities that routinely access the CNMM website were over-represented in the survey.

Information error may also have occurred, since the study worked with a self-administered questionnaire subject to interpretations, sometimes not completely accurate. In summary, the present study analyzed the profile of health professionals considered as under-reporters, allowing for better planning of measures to face these challenges and aiming at strengthening the national pharmacovigilance system, so that fair regulatory decisions are always taken, thus releasing safe, effective and quality medicines to the population.

\section{CONCLUSION}

The under-reporting rate of ADR among health professionals in Brazil found in this research was high. The highest percentage of underreporting was in the following groups: pharmacists and nurses, residents of the southern region and young people aged between 18 and 24 years old. Being a resident in the southern region of Brazil and not applying pharmacovigilance knowledge in professional practice was considered a risk factor for under-reporting, while having advanced knowledge in pharmacovigilance and notifying all suspected ADR cases are protective factors. It is logical to assume that expanding both the coverage and the content of training in pharmacovigilance in health courses, associated with a stronger connection between pharmacovigilance services and Brazilian universities, are also strategic actions to achieve the goal of increase scientific knowledge on drug safety for a greater awareness of the importance of ADR reporting and for academic interest in this field.

\section{ACKNOWLEDGEMENT}

The authors would like to thank the Anvisa Pharmacovigilance Management team for the support received and Sindusfarma, the Union of the Pharmaceutical Products Industry for their collaborations and the disseminating the research among your members.

\section{CONFLICT OF INTEREST}

The authors declare no conflicting interests.

\section{ABBREVIATIONS}

ADR: Adverse drug Reaction; OR: Odds Ratio; PV: Pharmacovigilance; WHO: World Health Organization; CNMM: National Drug Monitoring Center; Anvisa: Brazilian Health Regulatory Agency.

\section{REFERENCES}

1. Lopez-gonzalez E, Herdeiro MT, Figueiras A. Determinants of Under-Reporting of Adverse Drug Reactions. Drug-Safety. 2009;32(1):19-31.

2. Schurig AM, Böhme M, Just KS, Scholl C, Dormann H, Plank-Kiegele B, et al. Adverse drug reactions (ADR) and emergencies-the prevalence of suspected ADR in four emergency departments in Germany. Dtsch Arztebl Int. 2018;115(15):251-8.

3. Stausberg J. International prevalence of adverse drug events in hospitals: an analysis of routine data from England, Germany and the USA. BMC Health Serv Res. 2014;14(1):125

4. Organização Mundial da Saúde - OMS. Departamento de Medicamentos Essenciais e Outros Medicamentos. A importância da Farmacovigilância. Brasília: Organização Pan-Americana da Saúde (Monitorização da segurança dos medicamentos). 2005;48.

5. Oshikoya KA, Jacob OA. Perceptions of doctors to adverse drug reaction reporting in a teaching hospital in Lagos, Nigeria. BMC Clinical Pharmacology. 2009;9(1):14.

6. Noble DJ, Pronovost PJ. Underreporting of patient safety incidents reduces health care's ability to quantify and accurately measure harm reduction. J Patient Saf. 2010;6(4):247-50.

7. Stacey S, Coombes I, Wainwright C, Klee B, Miller H, Whitfield K. Medication events in children hospital. J Paediatr Child Health. 2014;50:966-71.

8. Hazell L, Shakir S. Under-reporting of adverse drug reactions: A systematic review. Drug Safety: An International Journal of Medical Toxicology and Drug Experience. 2006;29(5):385-96.

9. Mota Daniel Marques, Vigo Álvaro, Kuchenbecker Ricardo de Souza. Evoluçãoe elementos-chave do sistema de farmacovigilância do Brasil: Uma revisão de escopo a partir da criação da Agência Nacional de Vigilância Sanitária. Cad. Saúde Pública. 2018;34(10):e00000218. Disponível em: http://www.scielo.br/ scielo.php?script=sci_arttext\&pid=S0102-311X2018001002001\&Ing=pt.

10. Melo JRR, Duarte EC, Ferreira KA, Gonçalves YS, Moraes MV, Arrais PSD Assessment of Knowledge, Attitude and Practice of Pharmacovigilance among Healthcare Professionals in Brazil. J Young Pharm. 2020;12(3):255-60.

11. Shanko H, Abdela J. Knowledge, Attitudes and Practices of Health Care Professionals Toward Adverse Drug Reaction Reporting in Hiwot Fana Specialized University Hospital, Harar, Eastern Ethiopia: A Cross-sectional Study. Hosp Pharm. 2018;53(3):177-87.

12. Abdel-latif MM, Abdel-wahab BA. Knowledge and awareness of adverse drug reactions and pharmacovigilance practices among healthcare professionals in Al-Madinah Al-Munawwarah, Kingdom of Saudi Arabia. Saudi Pharm J. 2015;23(2):154-61.

13. Bhagavathula AS, Elnour AA, Jamshed SQ, Shehab A. Health Professionals' Knowledge, Attitudes and Practices about Pharmacovigilance in India: A Systematic Review and Meta-Analysis. PLoS One. 2016;11(3):e0152221.

14. Belton K. Attitude survey of adverse drug-reaction reporting by health care professionals across the European Union. E J Clin Pharmacol. 1997;52(6):423-7.

15. Inman WH. Attitudes to adverse drug-reaction reporting. Br J Clin Pharmacol 1996;41(5):433-5.

16. Irujo $M$, Beitia GB, Bes-rastrollo $M$, Hernández-Dias $S$, Figueiras $A$ Lascheras B. Factors that influence under-reporting of suspected adverse drug reactions among community pharmacists in a Spanish region. Drug Safety.2007;30(11):1073-82

17. Capucho HC, Arnas ER, Cassiani SHB. Segurança do paciente: comparação entre notificações voluntárias manuscritas e informatizadas sobre incidentes em saúde. Rev Gaúcha Enferm, Porto Alegre. 2013;34(1):164-72.

18. Kamtane RA, Jayawardhani V. Knowledge, Attitude and Perception of Physicians towards Adverse Drug Reaction (ADR) Reporting: A Pharmacoepidemiological Study. Asian J Pharm Clin Res. 2012;5(3):210-4.

19. Croesi B, Guarnone E, Calvi M. Farmacovigilanza: Le cause della sottosegnalazione nella fondazione IRCCS Policlinico San Matteo di Pavia. Giornale Italiano Di Farmacoeconomia e Farmacoutilizzazione. 2012;4(4):49-59. 